\title{
Alsterpaullone induces apoptosis of HepG2 cells via a p38 mitogen-activated protein kinase signaling pathway
}

\author{
PENG YIN ${ }^{*}$, NANXIN ZHENG $^{*}$, JUNFENG DONG ${ }^{*}$, CHUNYANG XU, XIAOMEI ZHANG and GUOSHAN DING \\ Department of Organ Transplantation, Changzheng Hospital, Shanghai 200003, P.R. China
}

Received February 25, 2018; Accepted October 24, 2018

DOI: $10.3892 / \mathrm{ol} .2018 .9700$

\begin{abstract}
Alsterpaullone (Alp) is a small-molecule inhibitor that targets cyclin-dependent kinases to inhibit tumor cell activity. However, to the best of our knowledge, the effect of Alp on hepatoblastoma has not been investigated. Therefore, the function of Alp in apoptotic induction of hepatoblastoma cells and a potential mechanism of action were investigated. Results indicated that low doses of Alp $(1 \mu \mathrm{M})$ significantly induced apoptosis in the HepG2 hepatoblastoma cell line. In vivo experiments of tumor suppression further indicated that Alp (3 $\mathrm{mg} / \mathrm{kg})$ exerted an inhibitory effect on HepG2 xenograft tumor growth. Following Alp treatment, the expression level of B-cell lymphoma 2 (Bcl-2)-associated X protein, and cleaved caspase-3 and -9 in HepG2 cells was significantly increased; however, the expression of Bcl-2 was significantly decreased. In addition, phosphorylation of p38 mitogen-activated protein kinase (MAPK) significantly decreased Alp-induced caspase- 3 and -9 activation. These results suggested that Alp induces apoptosis and inhibited proliferation via the $\mathrm{p} 38^{\mathrm{MAPK}}$ signaling pathway. Therefore, Alp may be a therapeutic agent for treating hepatoblastoma.
\end{abstract}

\section{Introduction}

Hepatoblastoma (HB) is the most common malignant liver tumor in children under 3 years of age (1). Epidemiological data indicate that the incidence of HB has increased in European countries, Japan and the USA in the last 30 years (2). HB is usually associated with constitutional genetic abnormalities, malformations and familial cancer syndromes $(3,4)$. Overall survival rates of patients with HB was relatively low (20-30\%) a few decades ago; however, the survival rates of these patients has increased to $70-80 \%$ because of the use of neoadjuvant

Correspondence to: Professor Guoshan Ding, Department of Organ Transplantation, Changzheng Hospital, 415 Fengyang Road, Shanghai 200003, P.R. China

E-mail: dingguoshanmail@163.com

*Contributed equally

Key words: alsterpaullone, HepG2 cells, apoptosis, p38, mitogen-activated protein kinase and adjuvant chemotherapy (2). Thus, novel chemotherapeutic treatments are critical for HB.

Cyclin-dependent kinase (CDK) inhibitors induce cell cycle arrest and promote apoptosis of tumor cells (5). Among all small-molecule CDK inhibitors, alsterpaullone (Alp; 9-nitro-7, 12-dihydroindolo[3,2-d][1]-benzazepin-6(5H)-one; Fig. 1A) is a paullone derivative confirmed to have increased potency in enzymatic and anti-proliferative assays compared with other derivatives (6,7). Alp inhibits a variety of tumors (5,8-11) and it selectively inhibits CDK1, resulting in cell cycle arrest at $\mathrm{G}_{2} / \mathrm{M}$ phase $(7,12)$. In addition, Alp can activate caspase- 9 via perturbation of the mitochondrial membrane potential, thereby inducing apoptosis in cancer cells $(8,9,13)$. Studies indicate that Alp also inhibits glycogen synthase kinase-3 $\beta$ (14-16).

To the best of our knowledge, the present study is the first to investigate the effect of Alp in the HB HepG2 cell line in an in vivo and in vitro model, and it was identified that Alp inhibited HepG2 cell proliferation via apoptosis and downregulated $\mathrm{B}$-cell lymphoma 2 (Bcl-2), upregulated $\mathrm{Bcl}-2$-associated $\mathrm{X}$ protein (Bax) and p38 mitogen-activated protein kinase (p38 $\left.8^{\mathrm{MAPK}}\right)$, and activated caspase- 3 and -9 . Thus, Alp may be useful for treating HB.

\section{Materials and methods}

Animals. A total of 27 male nude mice (4-6-week-old, 18-20 g) were purchased from the Experimental Animal Center of The Second Military Medical University (Shanghai, China) and housed in a continuous air laminar chamber in a specific pathogen-free animal facility in the Institute of Immunology of The Second Military Medical University with the following conditions: $28^{\circ} \mathrm{C}$, normal pressure, humidity of $40-60 \%$, and $10 \mathrm{~h}$ of light and $14 \mathrm{~h}$ without light daily. All animals had free access to water and food. All treatments complied with the animal welfare guidelines of Chinese Official Guiding Opinions on the Treatment of Experimental Animals and the Secondary Military Medical University. Experimental protocols for animal experiments were approved by the ethics committee of The Secondary Military Medical University.

Chemicals and reagents. Alp (purity 99\%) was dissolved in dimethylsulfoxide (DMSO; both Sigma Chemical Co.; Merck KGaA, Darmstadt, Germany) to concentrations of $10 \mu \mathrm{M}$ and $1 \mathrm{mg} / \mathrm{ml}$ and stored separately at $4^{\circ} \mathrm{C}$. The final concentration of DMSO in experimental culture medium 
was consistently $<0.1 \%$. A Cell Counting kit- 8 (CCK-8) was purchased from Dojindo Molecular Technologies, Inc. (Kumamoto, Japan). Dulbecco's modified Eagle's medium (DMEM) and fetal bovine serum (FBS) were obtained from Gibco; Thermo Fisher Scientific, Inc. (Waltham, MA, USA). A Fluorescein Isothiocyanate (FITC)-Annexin V/Propidium Iodide (PI) Apoptosis Detection kit and Hoechst 33342/PI were purchased from BD Biosciences (Franklin Lakes, NJ, USA) and Signalway Antibody LLC (College Park, MD, USA). Antibodies against cleaved caspase-3 (cat. no. sc-271759) and caspase-9 (cat. no. sc-133109) were obtained from Santa Cruz Biotechnology, Inc. (Dallas, TX, USA), antibodies against Bcl-2 (cat. no. BS1511), p38 (cat. no. BS3566), p-p38 (cat. no. BS4635) and Bax (cat. no. BS6420) were from Bioworld Technology, Inc. (St. Louis Park, MN, USA) and antibody against GAPDH (cat. no. SAB2108266) was from Sigma Chemical Co.; Merck KGaA. SB202190 (a p38-specific inhibitor; cat. no. 559388) was from EMD Millipore, Billerica, MA, USA. Cell lysis buffer was from Cell Signaling Technology, Inc. (Danvers, MA, USA), Protease Inhibitor Cocktail Tablets (cat. no. 617586) were from EMD Millipore and a Pierce ${ }^{\mathrm{TM}}$ Bicinchoninic Acid (BCA) Protein assay kit was from Thermo Fisher Scientific, Inc.

In vitro cell culture. A normal liver $\mathrm{LO} 2$ cell line and an $\mathrm{HB}$ HepG2 cell line were purchased from the Cell Bank of the Chinese Academy of Sciences (Shanghai, China). LO2 and HepG2 cells were cultured in DMEM containing 10\% FBS and incubated at $37^{\circ} \mathrm{C}$ under $5 \% \mathrm{CO}_{2}$.

CCK-8 assay. To determine the cytotoxicity of Alp towards the two cell lines at various concentrations for various durations of treatment, a CCK- 8 kit was used, according to the manufacturer's protocol. Briefly, each well of 96-well plate was seeded with $5 \times 10^{3}$ cells and cells were cultured until they reached $70-80 \%$ confluence. Alp $(0,0.5,1,1.5,2,5,10$ or $20 \mu \mathrm{M})$ was applied to cells and controls were treated with DMEM containing $10 \%$ FBS and $0.1 \%$ DMSO. Cells were incubated for 24,48 or $72 \mathrm{~h}$, and $10 \mu \mathrm{lCCK}-8$ solution was added to each well prior to incubation at $37^{\circ} \mathrm{C}$ for $40 \mathrm{~min}$. Sample absorbance was determined at $450 \mathrm{~nm}$ using an Epoch microplate spectrophotometer (BioTek Instruments, Inc., Winooski, VT, USA) and the half-maximal inhibitory concentrations $\left(\mathrm{IC}_{50}\right)$ were calculated.

Fluorescence staining. Hoechst 33342/PI double staining was performed to measure cytotoxicity of Alp in the two cell types. Cells $\left(1 \times 10^{5}\right.$ cells/well) were seeded on individual coverslips and incubated in 6 -well plates. DMSO $(0.1 \%)$ or Alp $(1,4$ or $8 \mu \mathrm{M}$ ) was added to wells prior to incubation at $37^{\circ} \mathrm{C}$ for $24 \mathrm{~h}$. The protocol was carried out as described previously (17). Cells for each treatment were stained with Hoechst 33342 dye for $20 \mathrm{~min}$ and subsequently stained with PI for $15 \mathrm{~min}$. Following three PBS washes, cells on coverslips were mounted on glass slides and observed under a fluorescence microscope (magnification, x200).

Annexin V/PI double staining. To determine the effect of Alp on HepG2 cell viability, Alp $(2,4$ or $8 \mu \mathrm{M})$ was applied to HepG2 cells for $24 \mathrm{~h}$ and $0.1 \%$ DMSO was used for controls. An FITC-Annexin V/PI Apoptosis Detection kit was used to determine levels of apoptosis. HepG2 cells $\left(2 \times 10^{5}\right.$ cells/well $)$ were seeded in individual wells of 6-well plates and treated as aforementioned. Cells were harvested and $100 \mu \mathrm{l} 1 \mathrm{X}$ binding buffer was used to resuspend cells, followed by labeling with $5 \mu 1$ FITC/annexin $\mathrm{V}$ and $5 \mu \mathrm{l} \mathrm{PI}$ at room temperature for $15 \mathrm{~min}$ in the dark. To each sample, $400 \mu \mathrm{l} 1 \mathrm{X}$ binding buffer was added prior to analysis by flow cytometry (Accuri ${ }^{\mathrm{TM}} \mathrm{C} 6$ instrument; BD Biosciences).

Colony formation assay. Colony formation is the basic ability of tumor cells (18). A cell colony formation assay was performed on HepG2 cells to verify the effect of Alp on HB cells. HepG2 cells were plated into $6 \mathrm{~cm}$ plates at $5 \times 10^{2}$ cells/well and were incubated at $37^{\circ} \mathrm{C}$ for $24 \mathrm{~h}$. The culture medium was removed, and fresh DMEM containing 10\% FBS and 0.1\% DMSO, or 2,4 or $8 \mu \mathrm{M}$ Alp was added. After $24 \mathrm{~h}$ of incubation at $37^{\circ} \mathrm{C}$, the medium was replaced with DMEM containing $10 \%$ FBS without DMSO or Alp. After 14 days of incubation at $37^{\circ} \mathrm{C}$, cells were washed twice with PBS, fixed in $2 \mathrm{ml} 4 \%$ paraformaldehyde for $30 \mathrm{~min}$, stained with $1 \mathrm{ml} 0.1 \%$ crystal violet for $20 \mathrm{~min}$ and washed three times with double-distilled water. The images of the plates were captured using a digital camera, and colonies with $<50$ cells were discounted. Each experiment was performed three times.

Western immunoblotting. HepG2 cells were treated with $0.1 \%$ DMSO and various concentrations $(2,4$ or $8 \mu \mathrm{M})$ of Alp for $24 \mathrm{~h}$. The cells were washed twice with ice-cold PBS and lysed with cell lysis buffer supplemented with protease inhibitor. Protein concentrations were determined using BCA assays. Equal amounts $(30 \mu \mathrm{g})$ of protein from each sample were separated by SDS-PAGE (10\% polyacrylamide gels), transferred electrophoretically onto a nitrocellulose membrane, and incubated in blocking buffer containing 5\% bovine serum albumin (Bio-Light Co., Ltd., Shanghai, China) in TBST for $1 \mathrm{~h}$ at room temperature. Nitrocellulose membranes were incubated with primary antibody overnight at $4^{\circ} \mathrm{C}$, washed and incubated with secondary antibody for $120 \mathrm{~min}$ at room temperature. Both peroxidase-conjugated AffiniPure goat anti-rabbit (cat. no. BS13278) and peroxidase-conjugated AffiniPure goat anti-mouse (cat. no. BS12478) secondary antibodies were purchased from Bioworld Technology, Inc. (St. Louis Park, MN, USA). Proteins were detected using chemiluminescence (Tanon Science and Technology Co., Ltd., Shanghai, China). The following antibody dilutions were used: Anti-GAPDH at 1:2,000; anti-cleaved caspase-3 and -9 at 1:200; anti-Bcl-2, -Bax, -p38 and -phospho (p)-p38 at 1:1,000. Both secondary antibodies of rat and mouse were used at 1:2,000. HepG2 cells were pretreated (or not) with $25 \mu \mathrm{M} \mathrm{SB} 202190$ for 45 min prior to treatment (or not) with $8 \mu \mathrm{M}$ Alp for $24 \mathrm{~h}$. Results were analyzed and quantified using ImageJ (version $1.49 \mathrm{v}$; National Institutes of Health, Bethesda, MD, USA).

In vivo tumorigenic experiments. To verify the effect of Alp on HepG2 cells in an in vivo model, a tumorigenic animal model was established using male nude mice. To establish experimental animals, 5x10 ${ }^{6}$ HepG2 cells were injected (subcutaneously) singly into the backs of nude mice and tumors were allowed to reach $\sim 3 \times 3 \mathrm{~mm}$. The optimal Alp dose was $3 \mathrm{mg} / \mathrm{kg}$ according to the results of the pre experiment (Alp dose 0, 0.5, 1, 1.5, 3, $5 \mathrm{mg} / \mathrm{kg}$ ) and this was administered to animals (intraperitoneally) 
A<smiles>O=C1Cc2c([nH]c3ccc([N+](=O)[O-])cc23)-c2ccccc2N1</smiles>
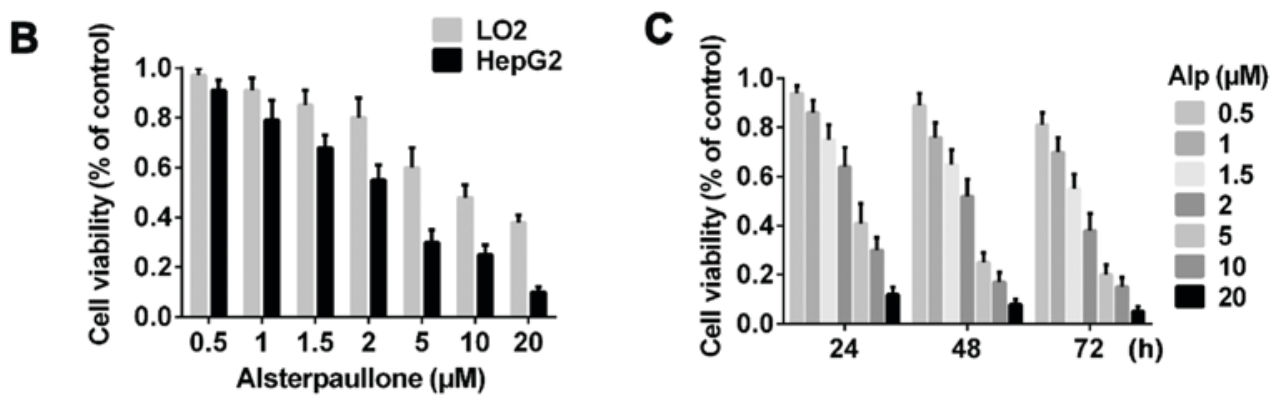

Figure 1. Alp time- and dose-dependently inhibits the proliferation of LO2 and HepG2 cells. (A) Chemical structure of Alp. (B) Viability analysis of LO2 and HepG2 cells incubated with various concentrations of Alp for $24 \mathrm{~h}$, as assayed using a Cell Counting kit-8 assay. (C) Viability of HepG2 cells incubated with $0,0.5,1,1.5,2,5,10$ or $20 \mu \mathrm{M}$ Alp for 24, 48 or $72 \mathrm{~h}$. The half-maximal inhibitory concentration of Alp for HepG2 cells was determined to be $3.095,2.333$ and $1.681 \mu \mathrm{M}$ at 24,48 and $72 \mathrm{~h}$, respectively. Results are presented as the mean \pm standard deviation $(\mathrm{n}=3)$. Results for each concentration and time point are significantly different $(\mathrm{P}<0.05)$ from those for all other concentrations and time points. Alp, alsterpaullone.
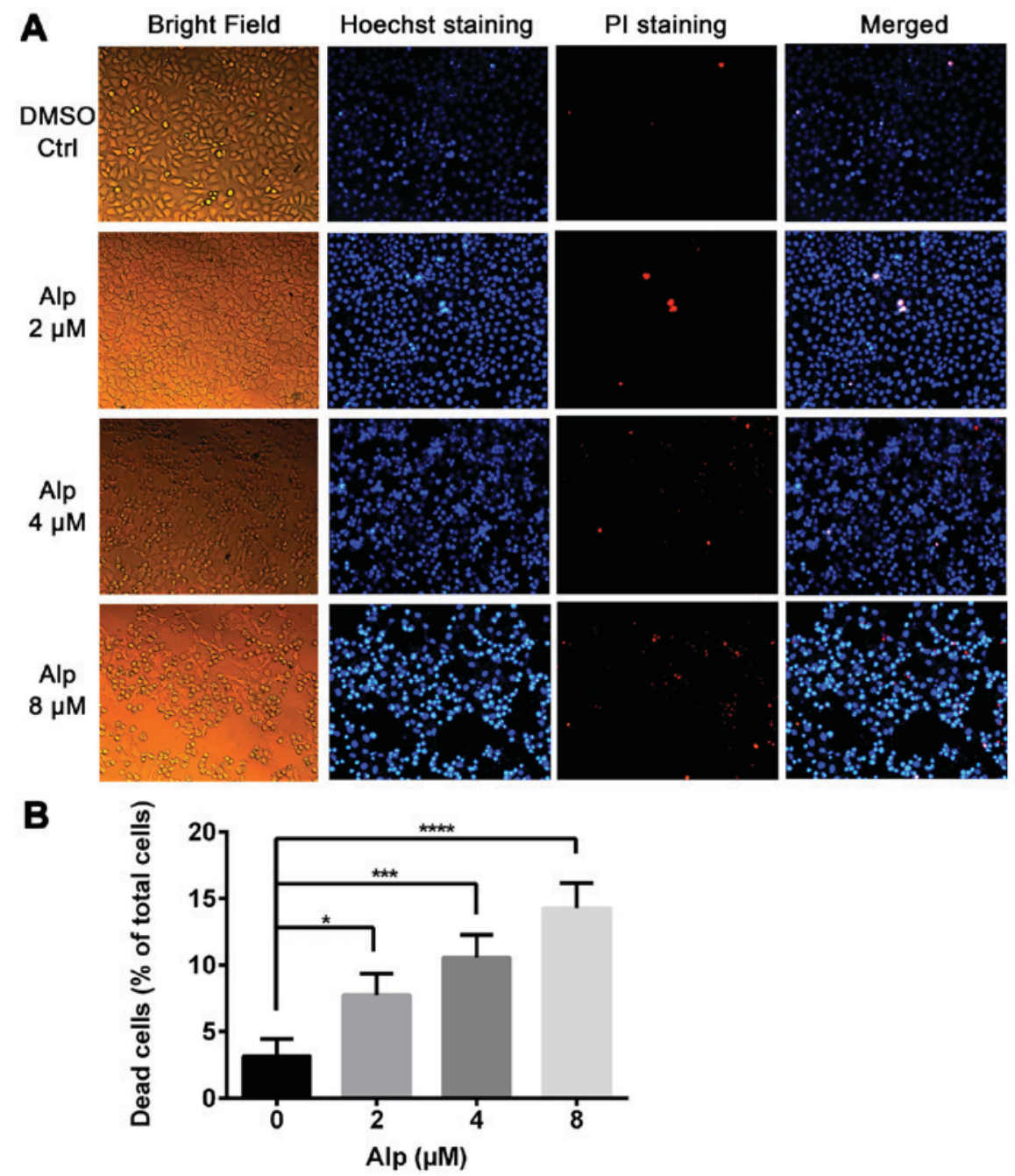

Figure 2. Alp induces death of HepG2 cells as visualized by fluorescence microscopy. (A) Hoechst 33342 and PI staining of HepG2 cells treated with the indicated concentrations of Alp for $24 \mathrm{~h}$ (original magnification, x200). (B) Quantification of dead cells relative to the total number of HepG2 cells treated with various concentrations of Alp for $24 \mathrm{~h}$. Results are presented as the mean \pm standard deviation for three separate experiments. ${ }^{*} \mathrm{P}<0.05,{ }^{* * * *} \mathrm{P}<0.001,{ }^{* * * * *} \mathrm{P}<0.0001$. Alp, alsterpaullone; PI, propidium iodide; DMSO, dimethylsulfoxide; Ctrl, control. 
once daily for 2 weeks. Nude control mice were given the same volume of $40 \%$ propylene glycol (Sigma Chemical Co.; Merck $\mathrm{KGaA}$ ). In total, 9 mice were used in each group. At the end of the experimental period, animals were sacrificed using $\mathrm{CO}_{2}$ (the flow rate was $250 \mathrm{ml} / \mathrm{min}$ and the volume of the cage was $1,000 \mathrm{~cm}^{3}$ ) and tumors were collected and analyzed.

Statistical analysis. GraphPad Prism software (version 6.0; GraphPad Software, San Diego, CA, USA) was used for statistical analyses and figure preparation. Experimental data are presented as the mean \pm standard deviation. Student's t-test was used to compare two groups and analysis of variance followed by a Dunnett's multiple comparisons test was used when more than three groups were analyzed. $\mathrm{P}<0.05$ was considered to indicate a statistically significant difference.

\section{Results}

Cytotoxicity of Alp in LO2 and HepG2 cells. Fig. 1B indicates that Alp exhibited significantly less inhibitory effect on LO2 normal liver cells compared with on HepG2 HB cells and these inhibitory effects were dose- and time-dependent. Fig. $1 \mathrm{C}$ presents the half-maximal inhibitory concentration data for 24, 48 and $72 \mathrm{~h}$ of incubation with Alp. Fig. 2A indicates that normal nuclei fluoresced blue following Hoechst 33342 staining and dead cells fluoresced red following PI staining. Cell morphology was altered with increasing Alp concentration. Alp significantly increased HepG2 cell death in a dose-dependent manner (Fig. 2B). Annexin V and PI double staining data presented in Fig. 3 indicated that that proportion of apoptotic HepG2 cells increased significantly with increasing Alp concentration, to a maximum at $8 \mu \mathrm{M}$ Alp $(\mathrm{P}<0.05)$.

Alp decreases colony formation in HepG 2 cells. Fig. 4 presents the results of a colony formation assay. The number of colonies of HepG2 cells treated with Alp at concentrations of $0,2,4$ and $8 \mu \mathrm{M}$ was $437 \pm 36,312 \pm 27,248 \pm 24$ and $153 \pm 28$, respectively, representing a significant decrease with increasing concentrations of Alp $(\mathrm{P}<0.05)$.

Alp induces the activation of caspase-3 and -9 in Hep G2 cells. To elucidate whether Alp-induced apoptosis was associated with caspase- 3 or -9 , levels of these enzymes were determined and, as presented in Fig. 5, caspase-3 and -9 cleavage in HepG2 cells was dose-dependent. Cleaved caspase-3 and -9 expression increased in HepG2 cells following $8 \mu \mathrm{M}$ Alp treatment. Bax expression also increased, whereas Bcl-2 expression decreased following Alp treatment.

Alp induces HepG2 apoptosis via p38 pathways. Fig. 6A indicates that, whereas total p38 expression levels in HepG2 cells were consistent, phospho-p38 levels increased with increasing concentrations of Alp. HepG2 cells treated with $25 \mu \mathrm{M}$ SB202190, a p38 ${ }^{\mathrm{MAPK}}$ inhibitor, prior to $8 \mu \mathrm{M}$ Alp treatment for $24 \mathrm{~h}$ exhibited weak casapase-3 and -9 activity (Fig. 6B).

Inhibitory effect of Alp on HB xenograft tumor growth. HB xenografts isolated from nude mice following sacrifice were weighed and images were captured. Fig. 7 presents representative images of $\mathrm{HB}$ xenografts and tumor weights from
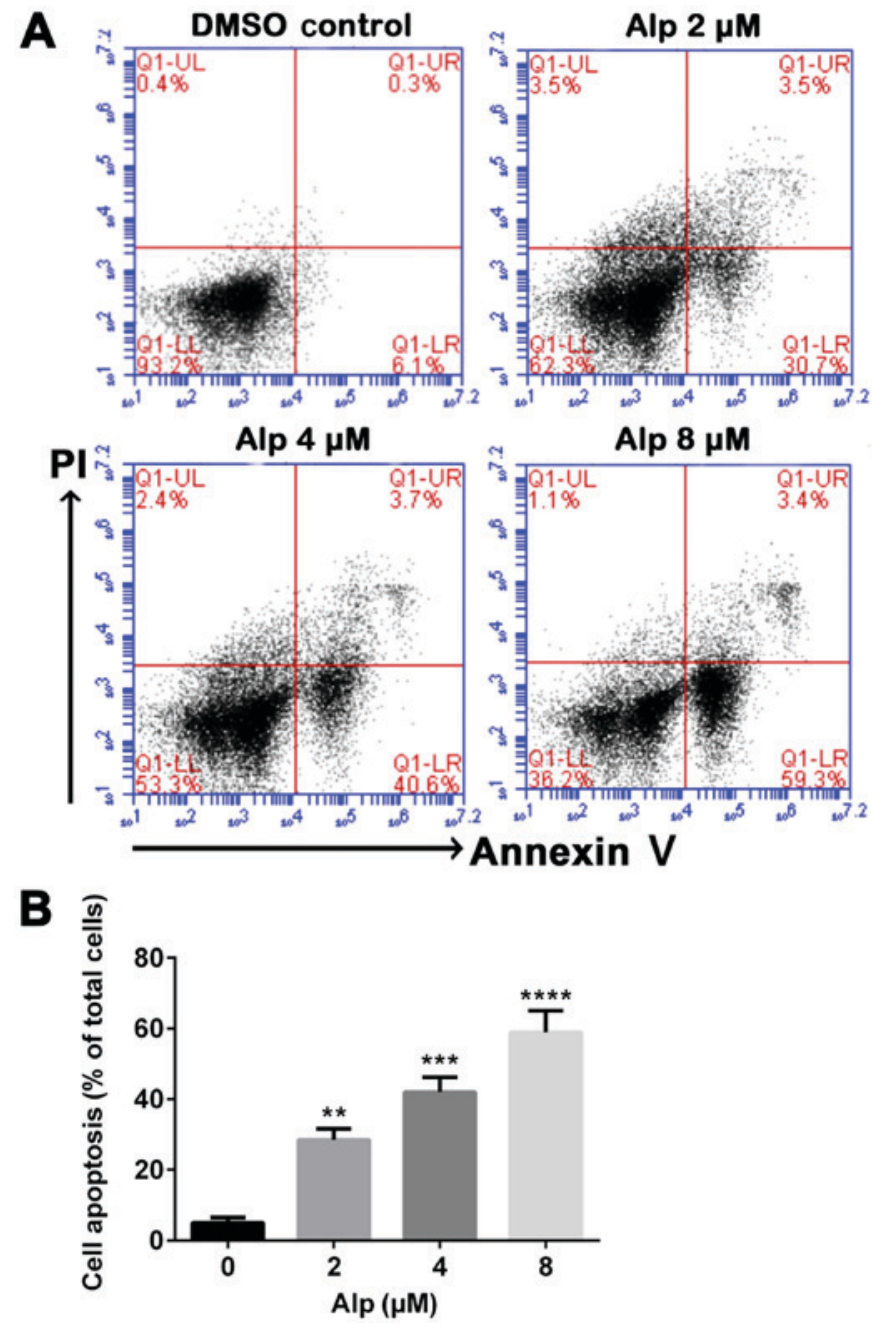

Figure 3. Alp induces dose-dependent apoptosis of HepG2 cells. (A) HepG2 cells were incubated with increasing concentrations of Alp for $24 \mathrm{~h}$, prior to analysis of cell apoptosis by flow cytometry. (B) Quantification of apoptotic HepG2 cells after $24 \mathrm{~h}$ of treatment with Alp at various concentrations. Results are presented as the mean \pm standard deviation for at least three independent experiments. ${ }^{* *} \mathrm{P}<0.01,{ }^{* * * *} \mathrm{P}<0.001,{ }^{* * * * *} \mathrm{P}<0.0001$ vs. control. Alp, alsterpaullone; DMSO, dimethylsulfoxide; PI, propidium iodide; UL, upper left; UR, upper right; LL, lower left; LR, lower right; Q, quadrant.

different treatment groups. Alp-treated animals had smaller tumors compared with those of PG-treated controls.

\section{Discussion}

$\mathrm{HB}$ is an embryonal tumor (3). Children with $\mathrm{HB}$ require complete surgical resection, but $\sim 50 \%$ of tumors are unresectable at diagnosis (19). Currently, prognosis is dismal with a low survival rate (20-30\%) (18). The use of pre-operative chemotherapy, surgical resection and post-operative chemotherapy has increased the survival rate to $70-80 \%$ (20). Therefore, novel chemotherapeutic drugs for HB are urgently required. Modulation of $\mathrm{CDKs}$ is considered to be critical to the treatment and prevention of human malignancies (6). Alp, a potent CDK modulator, competes with ATP for the CDK-binding site $(9,10)$, suggesting promise as a novel chemotherapeutic agent. Previous studies have identified antitumor effects of Alp in breast cancer, leukemia cells and cervical cancer $(5,8,10,11)$. In the present study, HepG 2 cells were selected to determine the 

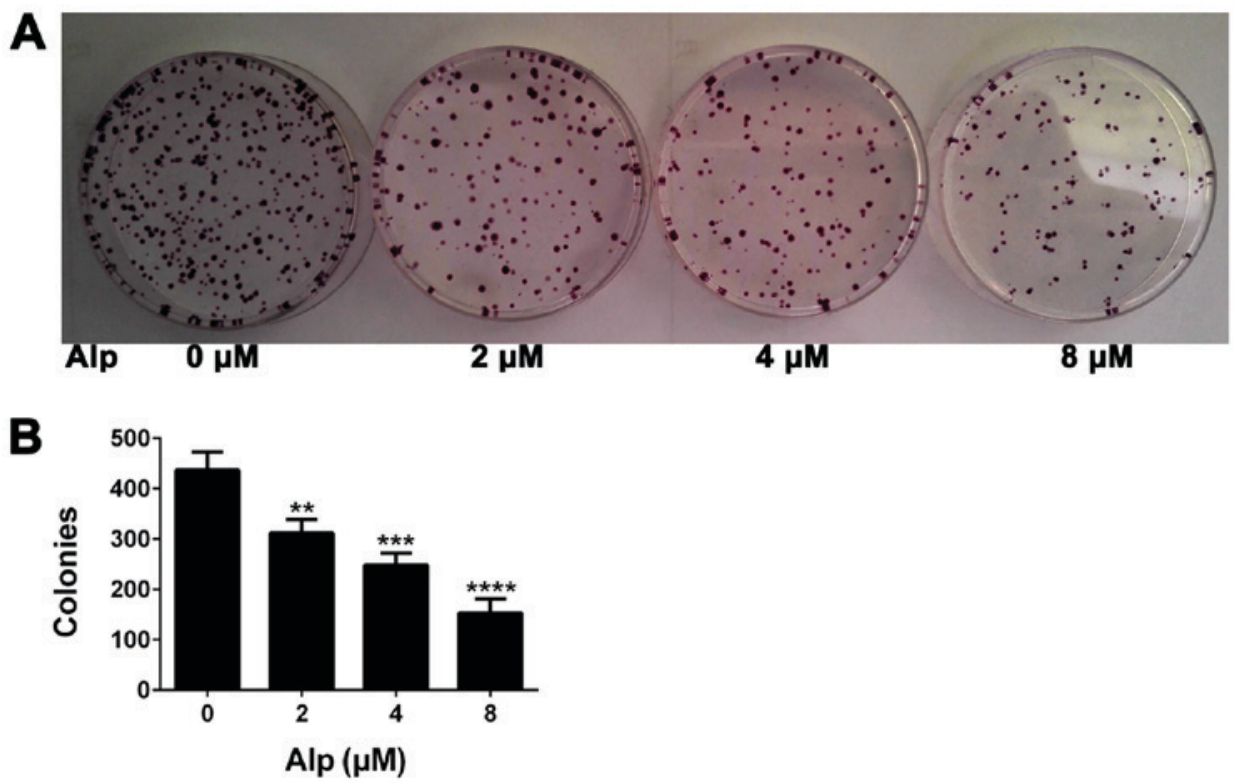

Figure 4. Alp decreases colony formation in HepG2 cells. (A) Colony-forming ability of HepG2 cells treated with various concentrations of Alp or with DMSO as a control. (B) Quantification of colonies formed following Alp treatment compared with DMSO-treated controls. Results are presented as the mean \pm standard deviation $(\mathrm{n}=3) .{ }^{* *} \mathrm{P}<0.01,{ }^{* * *} \mathrm{P}<0.001,{ }^{* * * *} \mathrm{P}<0.0001$ vs. control. Alp, alsterpaullone; DMSO, dimethylsulfoxide.
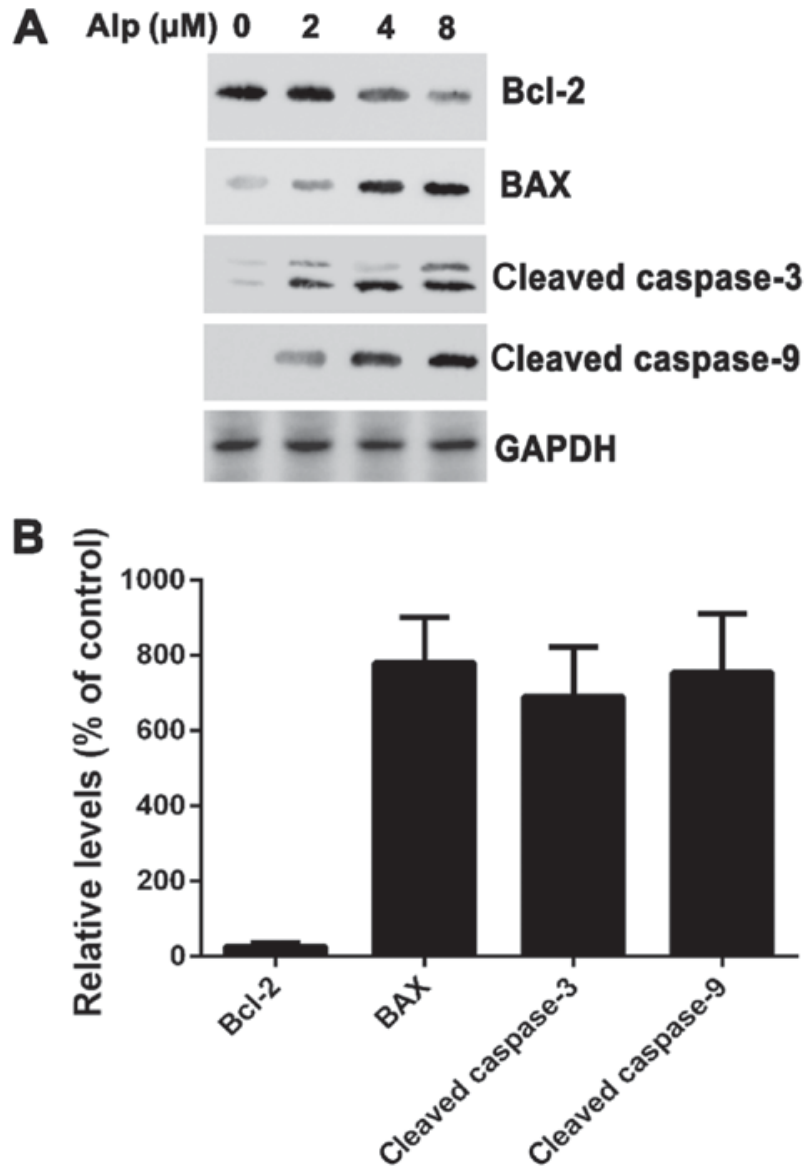

Figure 5. (A) HepG2 cells were treated with 2,4 or $8 \mu \mathrm{M}$ Alp for $24 \mathrm{~h}$ and subjected to western blotting. Bcl-2 was suppressed in Alp-treated HepG2 cells, whereas activation of caspase-3, caspase-9 and Bax was increased. (B) Following treatment with $8 \mu \mathrm{M}$ Alp for $24 \mathrm{~h}$, the relative expression levels of Bax, cleaved caspase-3 and cleaved caspase-9 in HepG2 cells were increased 7.8 $\pm 1.2-, 6.9 \pm 1.3$ - and 7.5 \pm 1.5 -fold, respectively. The relative expression level of $\mathrm{Bcl}-2$ was decreased $0.27 \pm 0.09$-fold. Results are presented as the mean \pm standard deviation $(\mathrm{n}=3)$. Alp, alsterpaullone; Bcl-2, B-cell lymphoma 2; Bax, Bcl-2-associated X protein. antitumor effects of Alp in HB. The HepG2 cell line, which has been widely used in biological fields, was originally classified as a cell line from hepatocellular carcinoma. Recently, HepG2 was reidentified as a HB-derived cell line (1). The results of the present study reveal for the first time, to the best of our knowledge, that Alp inhibited HepG2 cells in vitro and in vivo, offering significant cytotoxicity towards HepG2 cells in a doseand time-dependent manner. In a model of tumorigenicity using HepG2 cells in nude mice, Alp significantly decreased tumor weight at $3 \mathrm{mg} / \mathrm{kg}$. These results suggested that Alp exhibits significant antitumor effects in hepatic neoplasms.

Inhibition of cell proliferation is critical to apoptosis and blockade of cell cycle progression. Lahusen et al (8) first reported that Alp induced cell cycle arrest and also apoptosis in a Jurkat cell line. Additional studies indicated that Alp could induce apoptosis in various cell lines $(5,8,10,11)$, but the molecular mechanism by which Alp induces apoptosis in $\mathrm{HB}$ cells is unclear. Previous results indicate that apoptotic proteins participate in Alp-mediated HepG2 cell death, and that caspases and Bcl-2 family members may be critical to this apoptotic process $(21,22)$. Bcl-2 family proteins either suppress or promote apoptosis (23): Bcl-2 is an important anti-apoptotic protein, whereas Bax belongs to a pro-apoptotic subfamily (24). It was identified in the present study that Bax expression increased and Bcl-2 expression decreased following Alp treatment. Furthermore, caspases are indicators of apoptosis, and also critical regulators of initial apoptotic processes. Among the 14 caspases identified in mammals, caspase- 9 and -3 are essential for apoptosis $(21,22,25)$. Caspase- 9 , as an initiator caspase, can initiate a cascade of increasing caspase activity by processing and activating effector caspases (22). In addition, caspase-3, as an effector caspase, can cleave and inactivate certain vital cellular proteins by proteolysis $(22,26)$. Of note, Alp was identified to induce apoptosis by activating caspase- 9 and -3 , as well as by increasing the expression of cleaved caspase- 9 and -3 in HepG2 cells. 
A
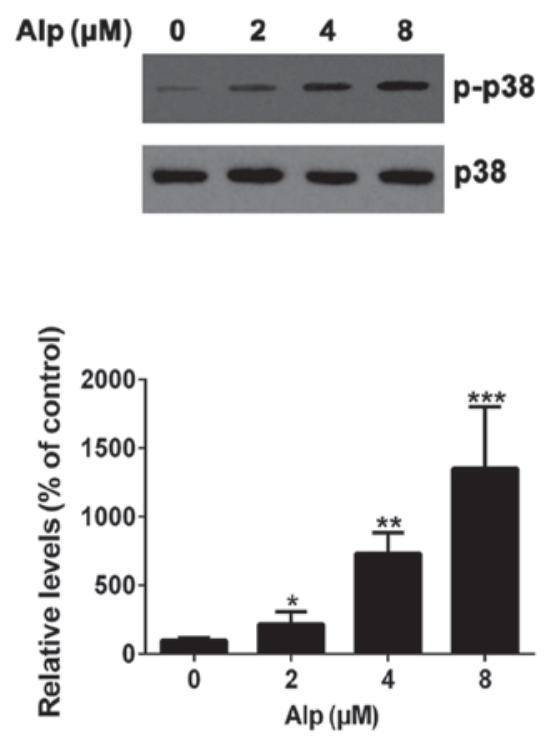
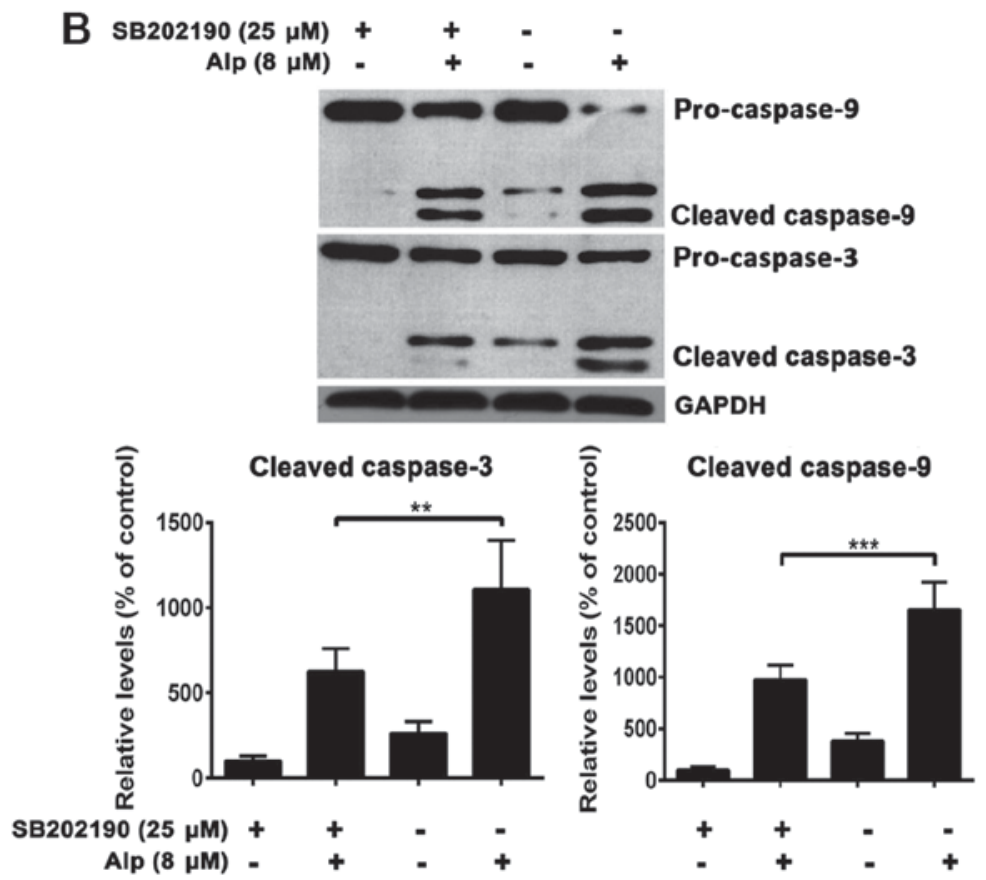

Figure 6. Alp induces HepG2 apoptosis via p38 signaling pathways. (A) The expression of p-p38 increased with increasing concentrations of Alp, whereas total p38 levels were consistent. Expression levels of p-p38 relative to vehicle control were increased 2.2 $\pm 0.9-, 7.3 \pm 1.5$ - and $13.5 \pm 4.4$-fold at 2,4 and $8 \mu \mathrm{M}$ Alp, respectively. (B) HepG2 cells were pretreated (or not) with $25 \mu \mathrm{M} \mathrm{SB} 202190$ for 45 min before treatment (or not) with $8 \mu \mathrm{M}$ Alp for $24 \mathrm{~h}$. The relative expression levels of Alp-induced caspase-3 and -9 activation were 6.3 \pm 1.4 - vs. 11.1 \pm 2.8 -fold and 9.7 \pm 1.4 - vs. $16.5 \pm 2.7$-fold with or without SB202190 treatment, respectively. Results are presented as the mean \pm standard deviation $(\mathrm{n}=3) .{ }^{*} \mathrm{P}<0.05,{ }^{* * *} \mathrm{P}<0.01,{ }^{* * * *} \mathrm{P}<0.001$ vs. control. Alp, alsterpaullone; $\mathrm{p}-$, phospho-

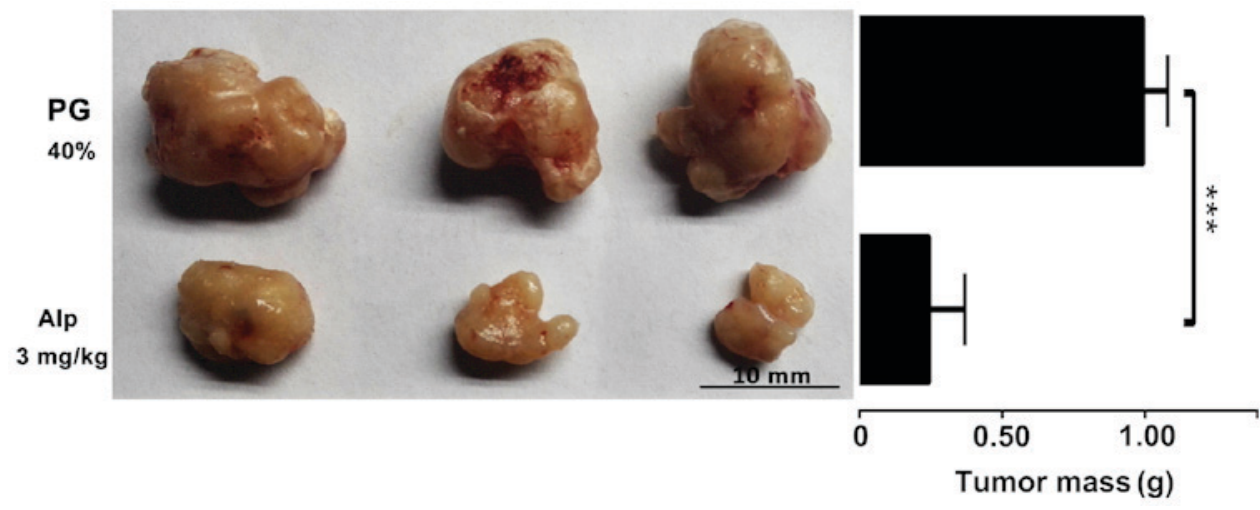

Figure 7. Inhibitory effect of Alp on HB xenograft tumor growth. HB xenografts were dissected from the nude mice treated with Alp or PG. Alp (3 mg/kg) significantly decreased the tumor weight. The mean tumor mass in Alp groups was $26 \pm 13 \%$ of that in the control. Representative images of HB xenografts from different treatment groups are presented. Results are expressed as the mean \pm standard deviation $(\mathrm{n}=9)$. ${ }^{* * * *} \mathrm{P}<0.001$. Alp, alsterpaullone; HB, hepatoblastoma; PG, propylene glycol.

MAPKs are involved in cell death (27), and activation of the MAPK signaling pathway serves a central function in HB proliferation and cell cycle progression (28). The $\mathrm{p} 38^{\mathrm{MAPK}}$ cascade is known to be involved in the apoptotic pathway of human HB cell lines and, compared with non-tumorous liver tissue, human HB cells have less $\mathrm{p} 38^{\mathrm{MAPK}}$ activity, suggesting that attenuation of $\mathrm{p} 38^{\mathrm{MAPK}}$ activity causes resistance to apoptosis in human HB cells. p38 $8^{\mathrm{MAPK}}$ activation has been identified to be associated with an apoptotic response induced by several anticancer agents (29). However, to the best of our knowledge, there have been no studies of the association between Alp, the MAPK signaling pathway and HB proliferation. Thus, p3 $38^{\text {MAPK }}$ activation was investigated in Alp-treated HepG2 cells. Results indicate that SB202190 (a p38 ${ }^{\mathrm{MAPK}_{-}}$-specific inhibitor) significantly inhibited the expression of caspase-3 and -9 induced by Alp, indicating that $\mathrm{p} 38^{\mathrm{MAPK}}$ is critical for Alp-induced apoptosis in HepG2 cells.

In summary, Alp inhibits the growth of $\mathrm{HB}$ in vivo and in vitro by inducing apoptosis via increasing caspase expression and modulating Bcl-2/Bax protein expression. Finally, the p38 $8^{\mathrm{MAPK}}$ pathway may be involved in HB apoptosis induced by Alp. Thus, Alp may hold promise as a novel chemotherapeutic agent for treating $\mathrm{HB}$.

\section{Acknowledgements}

The authors acknowledge Dr Meng Guo and Dr Fang Liu of the National Key Laboratory of Medical Immunology and Institute 
of Immunology (Shanghai, China) for the technical guidance of the colony formation assay and in vivo tumorigenic experiments.

\section{Funding}

This study was supported by the National Natural Science Funds of China (grant no. 81471575).

\section{Availability of data and materials}

All data generated or analyzed during this study are included in this published article.

\section{Authors' contributions}

GD designed the study, performed the experiments, supervised the project, drafted the manuscript, and reviewed and edited the final manuscript. PY collected the data, performed the experiments, drafted the manuscript, and reviewed and edited the final manuscript. NZ collected the data, performed data analysis, performed the experiments and drafted the manuscript. JD performed the experiments and data analysis, and drafted the manuscript. CX and XZ performed data analysis and visualization of the data.

\section{Ethics approval and consent to participate}

Experimental protocols for animal experiments were approved by the ethics committee of The Secondary Military Medical University.

\section{Patient consent for publication}

Not applicable.

\section{Competing interests}

The authors declare that they have no competing interests.

\section{References}

1. Ismail H, Broniszczak D, Kaliciński P, Dembowska-Bagińska B Perek D, Teisseyre J, Kluge P, Kościesza A, Lembas A and Markiewicz M: Changing treatment and outcome of children with hepatoblastoma: Analysis of a single centerexperience over the last 20 years. J Pediatr Surg 47: 1331-1339, 2012.

2. Czauderna P, Lopez-Terrada D, Hiyama E, Häberle B, Malogolowkin MH and Meyers RL: Hepatoblastoma state of the art: Pathology, genetics, risk stratification, and chemotherapy. Curr Opin Pediatr 26: 19-28, 2014.

3. Finegold MJ, Lopez-Terrada DH, Bowen J, Washington MK and Qualman SJ; College of American Pathologists: Protocol for the examination of specimens from pediatric patients with hepatoblastoma. Arch Pathol Lab Med 131: 520-529, 2007.

4. Cohen MM Jr: Beckwith-Wiedemann syndrome: Historical, clinicopathological, and etiopathogenetic perspectives. Pediatr Dev Pathol 8: 287-304, 2005.

5. Cui C, Wang Y, Wang Y, Zhao M and Peng S: Alsterpaullone, a cyclin-dependent kinase inhibitor, mediated toxicity in HeLa cells through apoptosis-inducing effect. J Anal Methods Chem 2013: 602091, 2013.

6. Schultz C, Link A, Leost M, Zaharevitz DW, Gussio R, Sausville EA, Meijer L and Kunick C: Paullones, a series of cyclin-dependent kinase inhibitors: Synthesis, evaluation of CDK1/cyclin B inhibition, and in vitro antitumor activity. J Med Chem 42: 2909-2919, 1999.
7. Martin CM and O'Leary JJ: Histology of cervical intraepithelial neoplasia and the role of biomarkers. Best Pract Res Clin Obstet Gynaecol 25: 605-615, 2011.

8. Lahusen T, De Siervi A, Kunick C and Senderowicz AM: Alsterpaullone, a novel cyclin-dependent kinase inhibitor, induces apoptosis by activation of caspase- 9 due to perturbation in mitochondrial membrane potential. Mol Carcinog 36: 183-194, 2003.

9. Rivest P, Renaud M and Sanderson JT: Proliferative and androgenic effects of indirubin derivatives in LNCaP human prostate cancer cells at sub-apoptotic concentrations. Chem Biol Interact 189: 177-185, 2011

10. Soni DV and Jacobberger JW: Inhibition of cdk1 by alsterpaullone and thioflavopiridol correlates with increased transit time from mid G2 through prophase. Cell Cycle 3: 349-357, 2004.

11. Faria CC, Agnihotri S, Mack SC, Golbourn BJ, Diaz RJ, Olsen S, Bryant M, Bebenek M, Wang X, Bertrand KC, et al: Identification of alsterpaullone as a novel small molecule inhibitor to target group 3 medulloblastoma. Oncotarget 6: 21718-21729, 2015.

12. Takai N, Kira N, Ishii T, Nishida M, Nasu K and Narahara H: Novel chemotherapy using histone deacetylase inhibitors in cervical cancer. Asian Pac J Cancer Prev 12: 575-580, 2011.

13. Arion VB, Dobrov A, Göschl S, Jakupec MA, Keppler BK and Rapta P: Ruthenium- and osmium-arene-based paullones bearing a TEMPO free-radical unit as potential anticancer drugs. Chem Commun (Camb) 48: 8559-8561, 2012.

14. Overington JP, Al-Lazikani B and Hopkins AL: How many drug targets are there? Nat Rev Drug Discov 5: 993-996, 2006.

15. Imming $P$, Sinning $C$ and Meyer A: Drugs, their targets and the nature and number of drug targets. Nat Rev Drug Discov 5: 821-834, 2006.

16. Berman HM, Westbrook J, Feng Z, Gilliland G, Bhat TN, Weissig H, Shindyalov IN and Bourne PE: The protein data bank. Nucleic Acids Res 28: 235-242, 2000.

17. Min J, Huang K, Tang H, Ding X, Qi C, Qin X and Xu Z: Phloretin induces apoptosis of non-small cell lung carcinoma A549 cells via JNK1/2 and p38 MAPK pathways. Oncol Rep 34: 2871-2879, 2015.

18. Watanabe K: Current chemotherapeutic approaches for hepatoblastoma. Int J Clin Oncol 18: 955-961, 2013.

19. Katzenstein HM, London WB, Douglass EC, Reynolds M, Plaschkes J, Finegold MJ and Bowman LC: Treatment of unresectable and metastatic hepatoblastoma: A pediatric oncology group phase II study. J Clin Oncol 20: 3438-3444, 2002.

20. Brown J, Perilongo G, Shafford E, Keeling J, Pritchard J, Brock P, Dicks-Mireaux C, Phillips A, Vos A and Plaschkes J: Pretreatment prognostic factors for children with hepatoblastoma-results from the International Society of Paediatric Oncology (SIOP) study SIOPEL 1. Eur J Cancer 36: 1418-1425, 2000.

21. Kumar S and Lavin MF: The ICE family of cysteine proteases as effectors of cell death. Cell Death Differ 3: 255-267, 1996.

22. Nicholson DW and Thornberry NA: Caspases: Killer proteases. Trends Biochem Sci 22: 299-306, 1997.

23. Oltvai ZN and Korsmeyer SJ: Checkpoints of dueling dimers foil death wishes. Cell 79: 189-192, 1994.

24. Strasser A, O'Connor L and Dixit VM: Apoptosis signaling. Annu Rev Biochem 69: 217-245, 2000.

25. Alnemri ES, Livingston DJ, Nicholson DW, Salvesen G, Thornberry NA, Wong WW and Yuan J: Human ICE/CED-3 protease nomenclature. Cell 87: 171, 1996.

26. Thornberry NA and Lazebnik Y: Caspases: Enemies within. Science 281: 1312-1316, 1998.

27. Park WH and Kim SH: MAPK inhibitors augment gallic acid-induced A549 lung cancer cell death through the enhancement of glutathione depletion. Oncol Rep 30: 513-519, 2013.

28. Esmaeili MA, Farimani MM and Kiaei M: Anticancer effect of calycopterin via PI3K/Akt and MAPK signaling pathways, ROS-mediated pathway and mitochondrial dysfunction in hepatoblastoma cancer (HepG2) cells. Mol Cell Biochem 397: 17-31, 2014.

29. Cui Y, Lu P, Song G, Liu Q, Zhu D and Liu X: Involvement of PI3K/Akt, ERK and p38 signaling pathways in emodin-mediated extrinsic and intrinsic human hepatoblastoma cell apoptosis. Food Chem Toxicol 92: 26-37, 2016.

This work is licensed under a Creative Commons Attribution-NonCommercial-NoDerivatives 4.0 International (CC BY-NC-ND 4.0) License. 